Military Technical College

Kobry El-Kobbah, Cairo, Egypt.

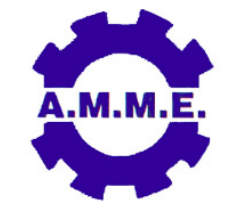

$17^{\text {th }}$ International Conference on Applied Mechanics and Mechanical Engineering.

\title{
VARIATION OF THE RESIDUAL STRESSES AND SPRINGBACK IN SHEET BENDING FROM PLANE-STRAIN TO PLANE-STRESS CONDITION USING FINITE ELEMENT MODELLING
}

\author{
A. Essa ${ }^{1}$, M.N.A. Nasr ${ }^{2}$ and M. H. Ahmed ${ }^{3}$
}

\begin{abstract}
Residual stresses (RS), springback and anticlastic curvature are the major concern after bending of sheet metal stripes. RS and springback are mainly affected by sheet width and material properties while anticlastic curvature is a consequential phenomenon associated only with narrow sections. The objective of this paper is to investigate the variation of $\mathrm{RS}$ with sheet width which changes from plane-strain condition for wider sheets to plane-stress condition for narrower sheets. The study of the springback is included to confirm the limit of the change from plane-strain to planestress condition. Investigation is based on finite element modelling (FEM) using ABAQUS/ Standard 6.10 to predict the influence of sheet width on RS, springback and anticlastic surface after three point bending. Analytical equation has been formulated to calculate the RS across the sheet thickness, and showed that RS is a function of sheet thickness, sheet width, strain hardening exponent $(\mathrm{n})$ and loading conditions. This equation has been compared to the FEM results and good agreement has been observed.
\end{abstract}

\section{KEYWORDS}

Finite element modelling (FEM); Residual stresses; Anticlastic curvature; Springback.

1 Research Assistant, Dept. of Prod. Engineering, Alexandria University, Alex, Egypt. Corresponding Author: E-mail: Abdelrahman.essa@alexu.edu.eg; Tel.:+20-0112-2267987.

2 Assistant Professor, Dept. of Mech. Engineering, Alexandria University, Alex, Egypt.

3 Associate Professor, Dept. of Production Engineering, Alexandria University, Alex, Egypt. 


\section{NOMENCLATURE}

$\begin{array}{ll}\mathrm{h} & \text { Sheet thickness } \\ l & \text { Moment of inertia } \\ \mathrm{k} & \text { Strength coefficient } \\ K_{s} & \text { Springback factor } \\ M_{l} & \text { Loading moment } \\ M_{u l} & \text { Unloading moment } \\ \mathrm{N} . \mathrm{A} & \text { Neutral axis } \\ \mathrm{n} & \text { Strain hardening exponent } \\ \mathrm{w} & \text { Sheet width } \\ \mathrm{X}, \mathrm{Y}, \mathrm{Z} & \text { Co-ordinate axes } \\ \mathrm{y} & \text { Distance from N.A } \\ \varepsilon & \text { Plastic strain in direction X } \\ \sigma & \text { Loading stress in direction X } \\ \sigma^{*} & \text { Unloading stress in direction X } \\ \rho & \text { Radius of curvature in plane } \mathrm{X}-\mathrm{Y} \\ \rho^{\backslash} & \text { Radius of curvature in plane } \mathrm{Z}-\mathrm{Y}\end{array}$

\section{INTRODUCTION}

Bending is the most common of all sheet forming processes; it can be done mainly through three point bending, using form dies or by roll forming [1]. Figure.1, shows the three point bending process and the deformation in both longitudinal and transversal directions. It is known that strain hardening materials retain significant residual stresses after unloading of bending load as shown in Fig.2. The residual stresses magnitude and sign in the direction of sheet length when the entire cross section is plastically deformed, depends mainly on the difference between amount of the nonlinear plastic deformation during loading and the linear elastic recovery during unloading [2].

Residual Stresses have significant effect on the part performance during service conditions. They can be beneficial or harmful, depending on the sign and location of the residual stresses [3]. Compressive residual stress squeezes the surface grain boundaries together and will significantly delay the initiation of fatigue cracking and increase the resistance to fatigue failure. Tensile residual stresses, on the other hand, attempt to stretch the surface apart and may lead to crack initiation, corrosion fatigue, stress corrosion cracking and hydrogen assisted cracking of the bent sections [4].

After bending, the final shape of the sheet will deviate from the desired shape due to springback as shown in Fig.3. Springback is one of the major quality concerns after sheet metal bending. If the shape deviation due to springback exceeds the specified tolerance, it can create serious problems for the subsequent assembly operations [5]. In the current work, springback is defined in terms of the springback factor $\left(K_{s}\right)$, which is the ratio between the initial sheet radius $\left(R_{i}\right)$ at the end of loading, and the final sheet radius $\left(R_{f}\right)$ after relaxation as shown in Fig.3. The Springback factor $\left(K_{s}\right)$ is calculated using Equation (1), where $\left(X_{1}, Y_{1}\right)$ and $\left(X_{2}, Y_{2}\right)$ are the coordinates of two nodal points on the surface of the bent sheet [6]. 
$K_{S}=\frac{R_{i}}{R_{f}}=\frac{\left.\left[\left(X_{2}-X_{1}\right)^{2}+\left(Y_{2}-Y_{1}\right)^{2}\right] / 2\left(Y_{2}-Y_{1}\right)\right]_{i}}{\left.\left[\left(X_{2}-X_{1}\right)^{2}+\left(Y_{2}-Y_{1}\right)^{2}\right] / 2\left(Y_{2}-Y_{1}\right)\right]_{f}}$

After bending, if the cross section remains rectangular, it will constrain the material to deform in the direction of sheet width; the strain in this direction will be zero as shown in Fig.1-b, and this occurs in case of wide sheet (plane-strain condition). However, for plane-stress condition, due to Poisson's ratio $(v)$, the compressive stress at the upper surface produces a lateral elongation of the upper layers of the beam cross section while the tensile stress at the lower surface produces a lateral retraction of the lower layers of the beam cross section. The section distorts as shown in Fig.1-c. This effect is known as anticlastic bending [7]. When a beam is bent to a radius of curvature $\rho$, as shown in Fig.1, the pure bending in opposite direction to axial bending, with a larger radius of curvature can be described as; $\rho \backslash=\frac{\rho}{v}$, where $\rho=(\mathrm{R}+\mathrm{q} . \mathrm{t})$, where q is constant which varied between 0.33 to 0.5 [8]. So, when designing the bending beam; we should check if the anticlastic curvature influences the beam function or not [9].

Research in modelling of sheet metal bending started decades ago. $\mathrm{OH}$ et. al. [10] used two FE models based on rigid-plastic analysis and elastic-plastic analysis to simulate the RS and springback after plane strain sheet bending, and suggested that rigid-plastic analysis can be applied successfully when there are large undeforming regions. TAN et. al. [11] used the layer removal method to determine the residual stress across thickness and they reported that the RS depends on work hardening. Khiabani et. al. [12] used the FEM to study the residual stresses of the thick plates; the results had shown that the RS have maximum value at the surfaces for the strain hardening material. Spoorenberg et. al. [13] have established a numerical model to estimate residual stresses in curved wide flange sections, and pointed out that the mesh density had a great effect on the FEM results.

Chuantao Wang et. al. [14] established mathematical models for plane-strain sheet bending to predict springback, strain and stress distributions, and noted that to obtain a reasonable accuracy the non-linear (true) stress distribution across the sheet thickness, strain hardening, and material anisotropy should be considered in the model. Chan et. al. [15] used the FEM to study the spring-back in V-bending. The analysis showed that springback is dependent on punch geometry, and they also noted that to achieve good accuracy, true stress distribution and anisotropy should be taken into consideration. Tekaslan et. al. [16] determined experimentally the springback of sheet metals on V-bending dies. The results showed that an increase in the thickness of the sheet and bending angle increase springback values. Jian et. al. [17] have derived an equation to predict the springback for wide sheet after sheet bending using form dies, and reported that the geometry of the sheet and punch as well as material properties influence the amount of springback. Panthi et. al. [18] proposed an analytical model for predicting the springback in sheet bending using form dies; they reported that the springback was affected by geometry and material properties of the sheet as well as the applied load during the bending. Horrocks and Johnson [19] carried out experimental investigations into the anticlastic curvature of plastically bent plates of varying widths and constant thickness; they reported that the transverse strain equals zero if the width to thickness ratio was at least eight.

In this paper, FEM has been developed and verified by an analytical equation which is developed to calculate the residual stresses across the thickness in the direction $\mathrm{X}$, 
(refer to Fig.1). Then the effect of sheet width on the residual stress, springback and anticlastic surface has been studied.

\section{ANALYTICAL MODELLING}

An analytical equation has been derived to calculate the loading stress distribution and residual stress across the sheet thickness. The equation is based on equating the loading moment to the un-loading moment about the N.A.

$M_{l}=2 \mathrm{w} \int_{0}^{h / 2} \sigma \cdot y \cdot d y$

Since the plastic stress strain curve is described by the power law

$$
\sigma=k \varepsilon^{n}
$$

where

$\varepsilon=\frac{y}{\rho}$

Combining equations (3) and (4) yields

$\sigma=\mathrm{k} \cdot\left(\frac{y}{\rho}\right)^{n}$

By substituting equation (5) in equation (2), and after integration

$$
M_{l}=\left(\frac{2 w K}{\rho^{n}}\right)\left(\frac{1}{n+2}\right)\left(\frac{h}{2}\right)^{n+2}
$$

or

$\frac{1}{\rho^{n}}=\left(\frac{M_{l}}{2 w k}\right)\left(\frac{n+2}{1}\right)\left(\frac{2^{n+2}}{h^{n+2}}\right)$

By substituting equation (7) in equation (5),

$$
\sigma=\frac{M_{l} \cdot y^{n}}{\frac{w \cdot h^{n+2}}{(n+2) \cdot 2^{n+1}}}=\frac{M_{l} \cdot y^{n}}{I_{n}}
$$

where $I_{n}=\frac{w \cdot h^{n+2}}{(n+2) \cdot 2^{n+1}}$

The final form of loading moment is,

$$
M_{l}=\frac{\sigma \cdot I_{n}}{y^{n}}
$$

Since the unloading stress must be linearly elastic, the unloading moment will be: 
$M_{u l}=\frac{\sigma^{*} . I}{y}$

By equating the loading moment with the unloading moment, one gets:

$\frac{\sigma^{*} . I}{y}=\frac{\sigma \cdot I_{n}}{y^{n}}$

which yields:

$\sigma^{*}=\frac{12 \cdot \sigma \cdot h^{n-1} \cdot y^{1-n}}{(n+2) \cdot 2^{n+1}}$

By subtracting the loading stress from the unloading stress, one can obtain the residual stress:

$\mathrm{RS}=\sigma^{*}-\sigma$

\section{FINITE ELEMENT MODELLING}

A 3D FEM has been developed using ABAQUS/Standard 6.10 to simulate the three point bending process of low carbon annealed steel (AISI 1020) in order to investigate the effect of sheet width on residual stresses, springback and anticlastic curvature. Also 2D models have been developed for plane-strain and plane-stress elements in order to compare their predicted RS with the analytical equation's result. The process was performed over two simulation steps; the first step simulated the bending process (loading step), while the second one simulated the stress-relaxation process to obtain the residual stress (relaxation step).

\section{Model Geometry, Material and Boundary Conditions (BCs)}

Figure.4, shows the basic geometry of the FE model used to simulate 3-point bending, where the sheet has supported length of $80 \mathrm{~mm}$, thickness of $5 \mathrm{~mm}$ and variable width of $120 \mathrm{~mm}$ to ensure plane-strain condition, to $10 \mathrm{~mm}$ to ensure plane-stress condition. The punch has a radius of $15 \mathrm{~mm}$ and the support has a radius of $5 \mathrm{~mm}$. The sheet is made of annealed low carbon steel AISI 1020, the properties of which are presented in Table 1, while the punch and supports are modeled as rigid bodies. Only quarter of the setup is modeled with the aid of symmetric boundary conditions. The supports were fixed in all directions, while the punch was moved in the vertical direction ( $\mathrm{Y}$ ) with specific value equal $10 \mathrm{~mm}$ which ensures full plasticity across the thickness for the maximum selected sheet width (i.e. $120 \mathrm{~mm}$ ).

\section{Analysis Type}

An implicit, mechanical analysis has been used in both simulation steps: the loading step and the stress-relaxation step. Thermal and strain rate effects were not included because the deformation speed is very low and the generated heat can be ignored due 
to its little effect. Contact surface pair is defined between two surfaces that are in contact during the loading step. Due to the ease of sliding between the sheet and supports, low coulomb friction coefficient has been assumed $(\mu=0.05)$. After the bending step, all the interactions with the sheet and the boundary conditions are removed in the relaxation step, and the sheet is left for relaxation for a period of time larger than deformation time to predict the residual stress.

\section{Meshing}

A 4-node bilinear plane strain quadrilateral, reduced integration (CPE4R), and 4-node bilinear plane stress quadrilateral, reduced integration (CPS4R) elements are used to mesh the sheet in the 2D FEM, while 8-node linear brick, reduced integration (C3D8R) are used to mesh the sheet in the 3D FEM. The 2D model is built with two element types; plane-strain and plane-stress elements to validate the analytical equation's results under both conditions.

\section{Mesh sensitivity analysis}

Mesh sensitivity analysis is carried out to ensure that the mesh size used is neither time consuming, nor leading to error in the results. The element size in the direction of sheet thickness is decreasing toward the sheet surfaces, while the element size in the direction of sheet length is increasing towards the free edges as shown in Fig.4. The optimum element size across the sheet thickness is $0.1^{*} 0.35 \mathrm{~mm}$ at the surface.

\section{RESULTS AND DISCUSSION}

The presented FEM is firstly validated. Current validation is based on comparing the $R S$ from FEM to the $R S$ from the analytical equation. Then the effects of sheet width on residual stresses, springback and anticlastic surface have been studied through 3D FEM.

\section{Model Validation}

Fig.5 and Fig.6, compares the 2D and 3D FEM results of the change of RS across the thickness to the corresponding analytical results, for each of plane-strain and planestress conditions, respectively. As shown, good match is found between 2D and 3D FEM results and the analytical solution especially at lower layers of the sheet thickness (stretched layers during bending), but there is some deviation between the analytical and FEM results at the upper layers of the sheet thickness (compressed layers during the bending). This could be due to the shift of neutral axis towards the compression side, which is ignored in the analytical equation.

\section{Effect of Sheet Width on the Residual Stresses}

Residual stress has been calculated for different sheet width from 120 to $10 \mathrm{~mm}$ in order to cover the range from plane-strain to plane-stress conditions. The results show 
that the sheet width has significant effect on the $R S$ across the thickness especially at the upper layers as shown in Fig.7. The results shown in Fig.8 represent the effect of sheet width on the RS at the upper and lower surfaces and across the thickness; all positions have exhibited the same trend. When the sheet width increases, the $R S$ increase until width to thickness ration w/h equals 8 (sheet width equals $40 \mathrm{~mm}$ ), then the RS start to decrease with further increase of the sheet width, suggesting that the $\mathrm{RS}$ is inversely proportional to sheet width for $w / h$ greater than 8 . This limiting ratio agrees with the results obtained by [19]. Figure.8, also shows that the maximum difference in the RS is found to be $32 \%$ between sheet widths $10 \mathrm{~mm}$ and $40 \mathrm{~mm}$ at the upper surface. Moreover, the maximum RS is tensile and existing on the upper surface of the sheet, which causes tendency for cracking of this surface if it is subjected to cyclic load during service. The Interpretation of the previous trend is shown in Fig.9, which presents the variation of the plastic strain in the direction of width, this strain reaches nearly zero value at width of $40 \mathrm{~mm}$, suggesting the onset of plane strain condition.

\section{Springback}

Figure.10, presents the effect of sheet width on springback factor $\left(K_{s}\right)$ in plane X-Y (as shown in Fig.3), where springback factor has been found to increase (i.e., less springback) with the increase of width up to a limiting width of about $40 \mathrm{~mm}$, beyond which it reaches a constant value of 0.97 for plane-strain condition. This suggests that the springback is relatively small for plane strain condition and increases significantly with the reduction of width (under plane stress condition). The figure confirms that the change from plane-strain to plane-stress condition is almost at $\mathrm{w} / \mathrm{h}$ ratio of about 8 .

\section{Anticlastic Surface}

The anticlastic curvature is calculated in terms of the maximum curvature height, and then plotted against the sheet width, as presented in Fig.11. The Figure indicates that under plane-stress condition, the curvature of the anticlastic surface increases sharply by about $70 \%$ when the sheet width decreases from $40 \mathrm{~mm}$ to $20 \mathrm{~mm}$. Note that if the width is lower than $20 \mathrm{~mm}$ the workpiece will no longer be a sheet, and will becomes a billet, in which case the previous trend will not be valid. Figure.12, shows three anticlastic surfaces: (a) in case of plane-strain condition, where there is no anticlastic behavior (b) transition from wide to narrow sheet and (c) in case of plane-stress condition.

\section{CONCLUSION}

Sheet width is one of the important parameters in the three point bending process, and has a great effect on residual stresses, springback and anticlastic surface. In this paper, FE model has been developed using (ABAQUS) to predict the effect of sheet width on residual stress distribution, springback and anticlastic surface. The model's results have been compared with a derived analytical equation that predicts the RS, and good agreement has been observed. From this research the following conclusions can be attained: 
- RS depend on sheet width, thickness, strain hardening exponent and loading condition.

- Sheet width has significant effect on the residual stresses across the thickness, especially on the compression surface of the bent sheet which experiences maximum tensile residual stresses.

- Residual stresses have maximum value when the sheet width is almost eight times the thickness, representing a limit between plane-strain conditions for wider sheets and plane-stress conditions for narrower sheets. This limit is confirmed by zero strains in the width direction for wider sheets.

- The springback is least under plane strain conditions, and increases significantly with the decrease of the width in the plane stress region.

- The cross section under the punch suffers anticlastic distortion in the planestress region of sheet width with higher distortion at lower widths.

\section{REFERENCES}

[1] Z. Marciniak, J.L. Duncan and S.J. Hu, "Mechanics of Sheet Metal Forming", Butterworth-Heinemann, (2002).

[2] E. J. Hearn, "Mechanics of material 2", Butterworth-Heinemann, (1997).

[3] Gary S. Schajer, "Practical Residual Stress Measurement Methods", John Wiley \& Sons Ltd, (2013).

[4] Metal Improvement Company, "Shot Peening Applications", INC. (2000).

[5] Dorel Banabic, "Sheet Metal Forming Processes", Springer-Verlag Berlin Heidelberg, (2010).

[6] S.K. Panthi et al, "An analysis of springback in sheet metal bending using finite element method (FEM)", J. of Materials Processing Technology, vol.186, pp. 120-124, (2007).

[7] T. H. G. Megson, "Aircraft Structures for engineering students", Elsevier Ltd, (2007).

[8] H. A. Youssef et al, "Manufacturing Technology", Taylor \& Francis Group, (2012).

[9] Stephen D. Senturia, "Microsystem Design”, Kluwer Academic Publishers, (2001).

[10] S. I. OH et al, "Finite Element Analysis of plane strain sheet bending", Int. J. Mech. Sci, vol. 22, pp. 583-594, (1979).

[11] Z. Tan et al, "On Analysis and Measurement of Residual Stresses in the Bending of Sheet Metals", Int. J. Mech. Sci, Vol. 36, pp. 483-491, (1994).

[12] C. Khiabani et al, "Finite element evaluation of residual stresses in thick plates", Int. J. Mech Mater Des, Vol. 5, pp. 253-261, (2009).

[13] R.C. Spoorenberg et al, "Finite element simulations of residual stresses in roller bent wide flange sections", Journal of Constructional Steel Research, Vol. 67, pp. 39-50, (2011).

[14] Chuantao Wang et al, "Mathematical modeling of plane-strain bending of sheet and plate", J. of Materials Processing Technology, Vol. 39, pp. 279304, (1993).

[15] W.M. Chan et al, "Finite element analysis of spring-back of V-bending sheet metal forming processes", J. of Materials Processing Technology, Vol. 148, pp. 15-24, (2004). 
[16] Ozgur Tekaslan et al, "Determination of spring-back of stainless steel sheet metal in "V" bending dies", J. of Materials and Design, Vol. 29, pp. 10431050, (2008).

[17] LI Jian et al, "Improvement of springback prediction of wide sheet metal air bending process", College of Mechanical Engineering, Yanshan University, Vol. 15, pp. 310-315, (2008).

[18] S. K. Panthi et al, "Semi analytical modeling of springback in arc bending and effect of forming load" transaction of nonferrous metal society of china, Vol. 21, pp. 2276-2284, (2011).

[19] D. Horrocks and W. Johnson, "ON Anticlastic Curvature with Special Reference to Plastic Bending: A Literature Survey and Some Experimental I Investigations", Int. J. Mechanical science, vol. 9, pp. 835-861, (1967).

[20] William D. Callister, Jr. "Material Science and Engineering", John Wiley \& Sons, Inc, (2007). 


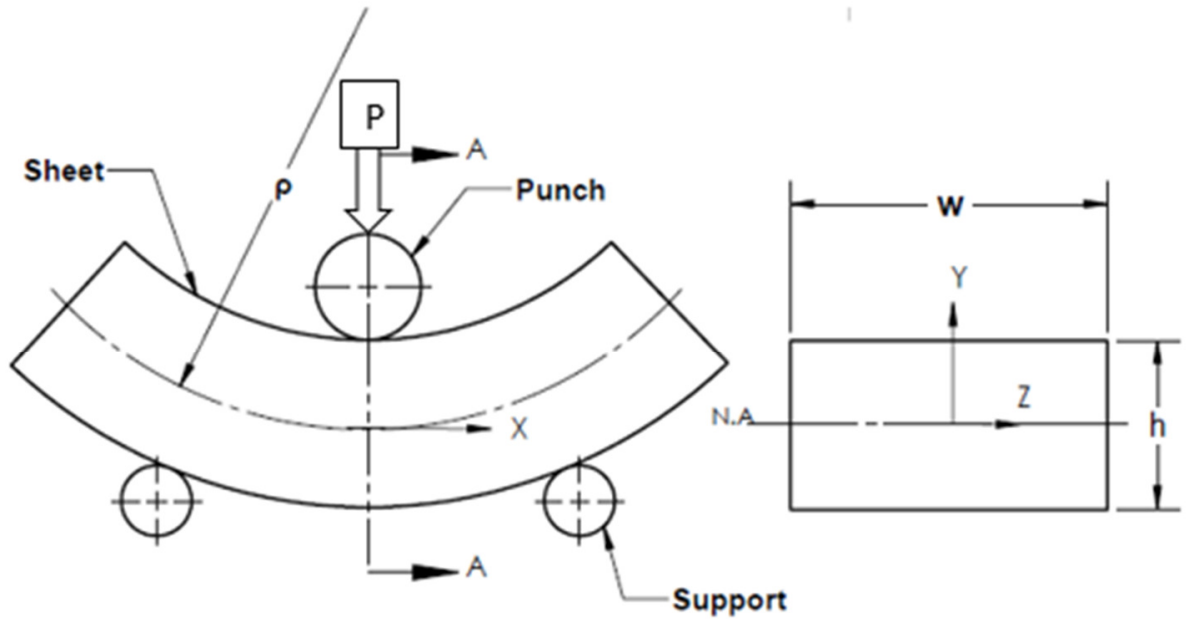

a b

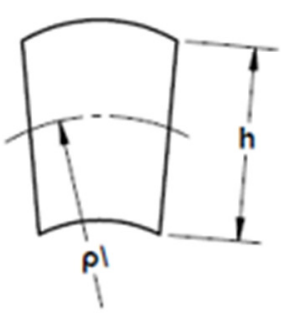

C

Fig.1. (a) Three point bending process, (b) cross section A-A in case of wide sheet, (c) cross section $A-A$ in case of narrow sheet.

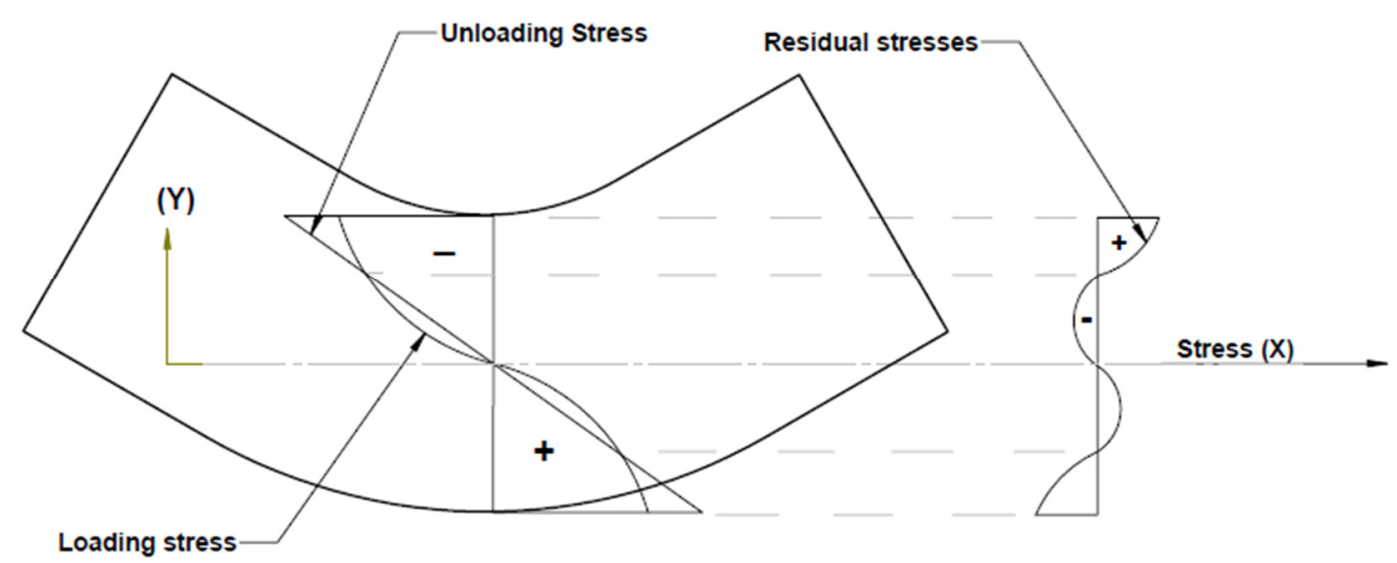

Fig.2. Schematic diagram showing residual stress generation for a strain hardening material.

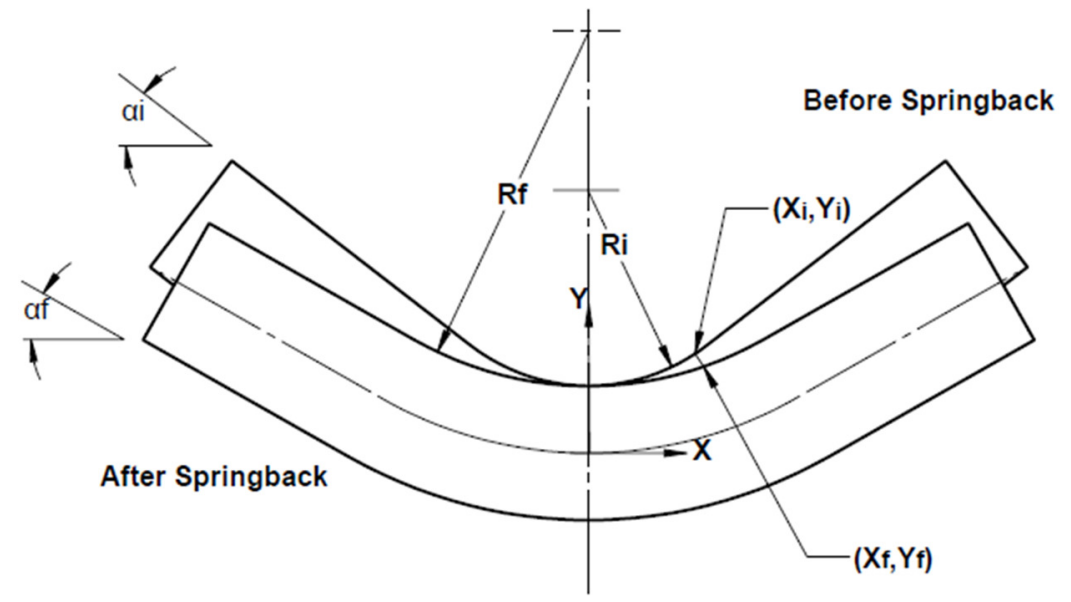

Fig.3. The bending sheet before and after the springback. 


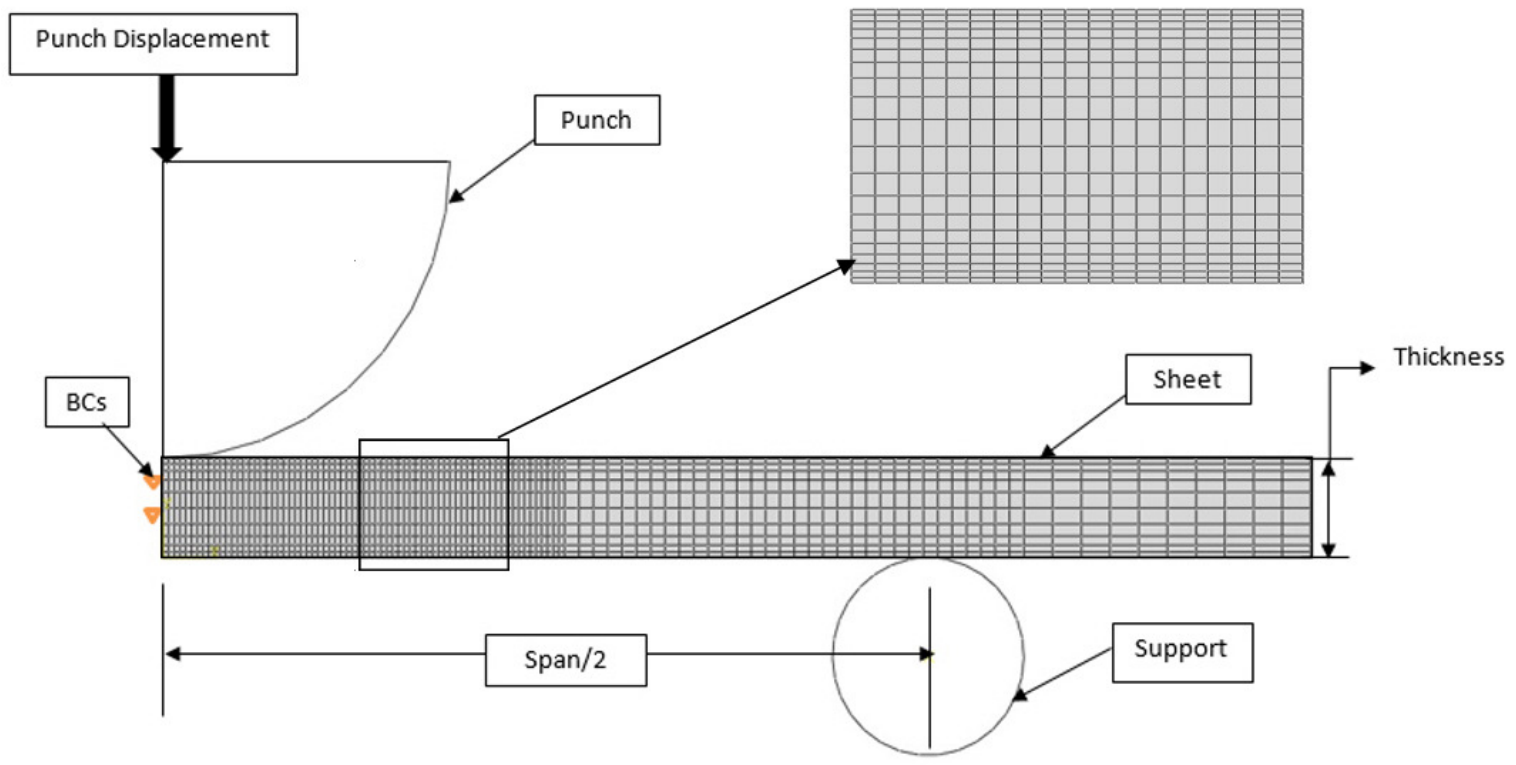

Fig. 4. Geometry of the quarter model with the applied BCs.

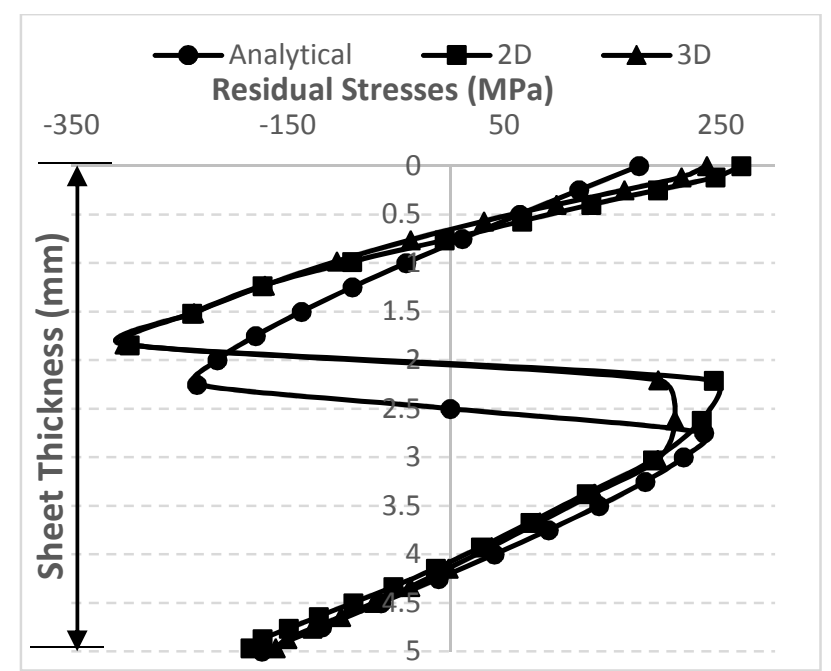

Fig.5. Residual stress of 3D FEM with sheet width $120 \mathrm{~mm}$, 2D FEM with plane strain element and analytical equation.

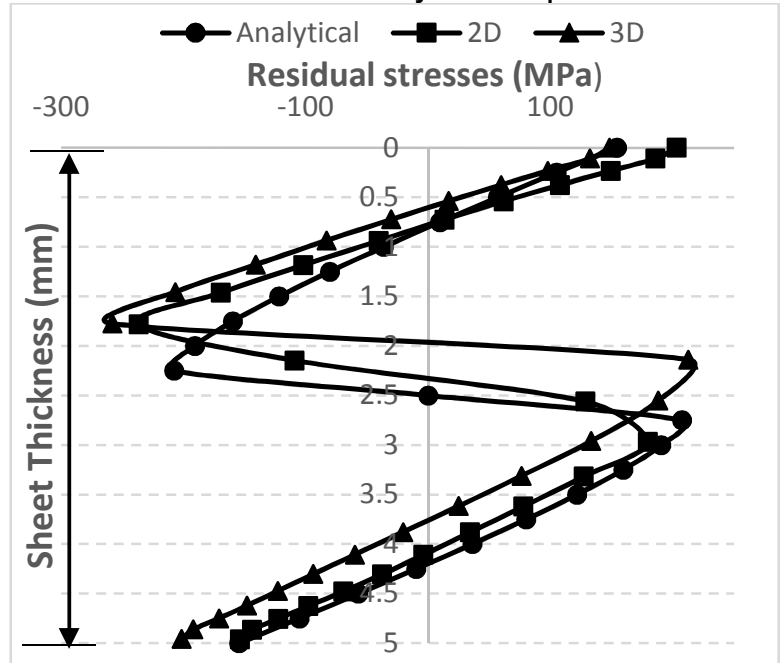

Fig.6. Residual stress of 3D FEM with sheet width $10 \mathrm{~mm}$, 2D FEM with plane stress element and analytical equation. 


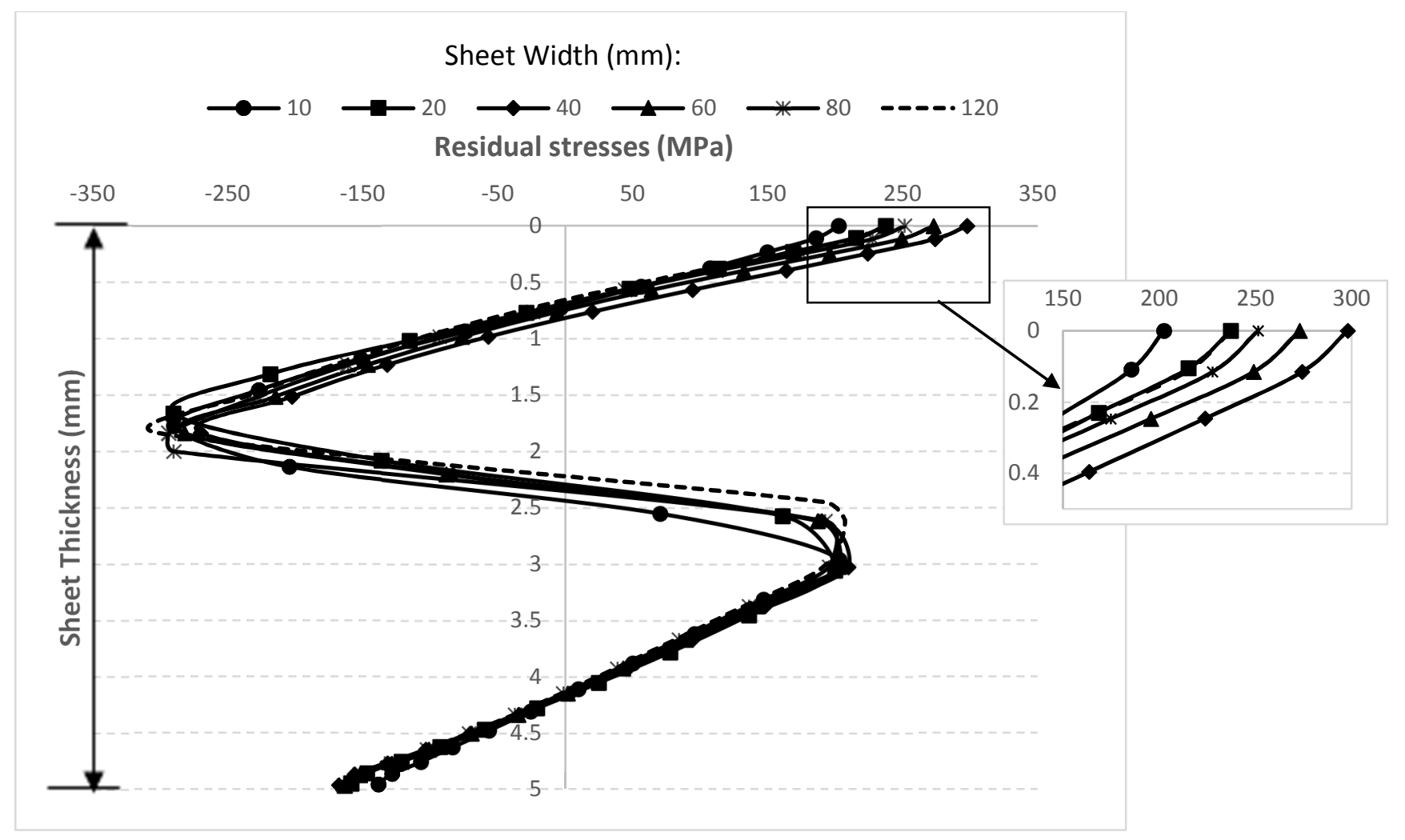

Fig.7. Residual stress for different sheet widths (mm).

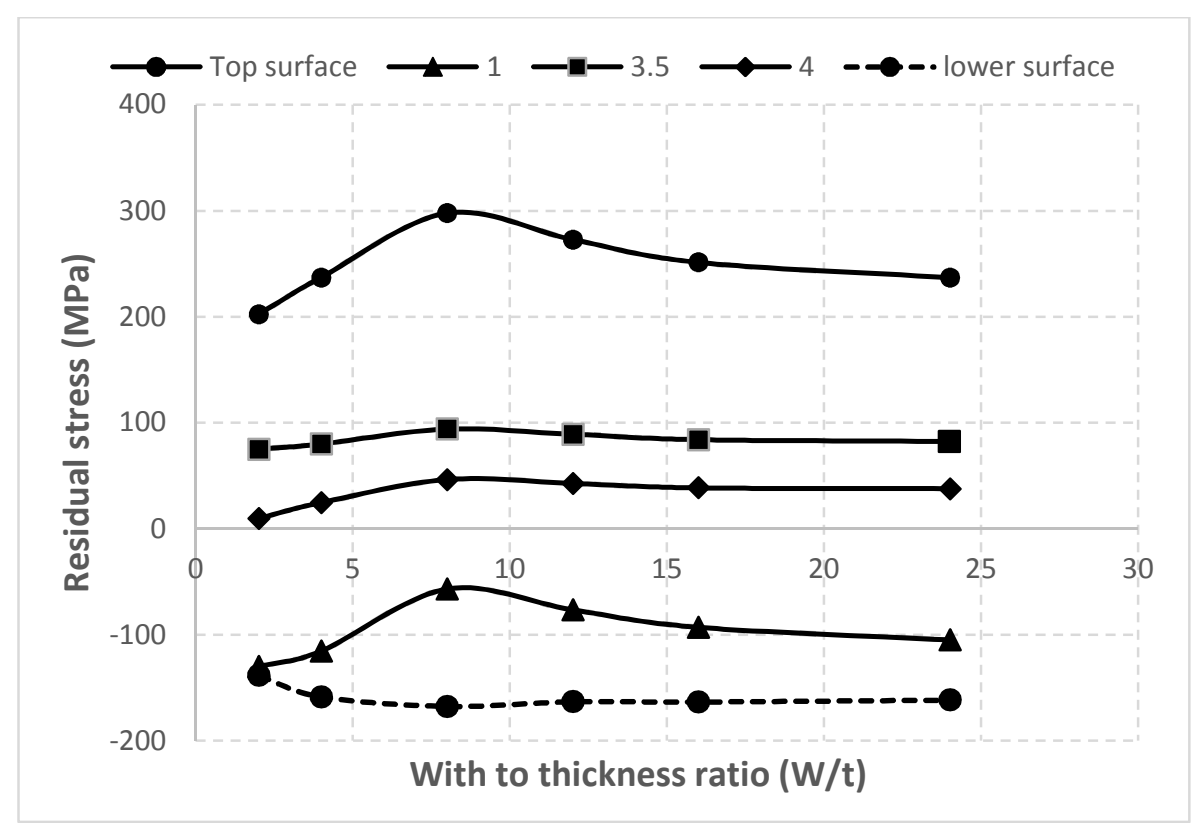

Fig.8. Relation between residual stresses and width to thickness ration $(w / h)$ at the upper surface, $1 \mathrm{~mm}, 3.5 \mathrm{~mm}, 4 \mathrm{~mm}$ from the upper surface and at the lower surface. 


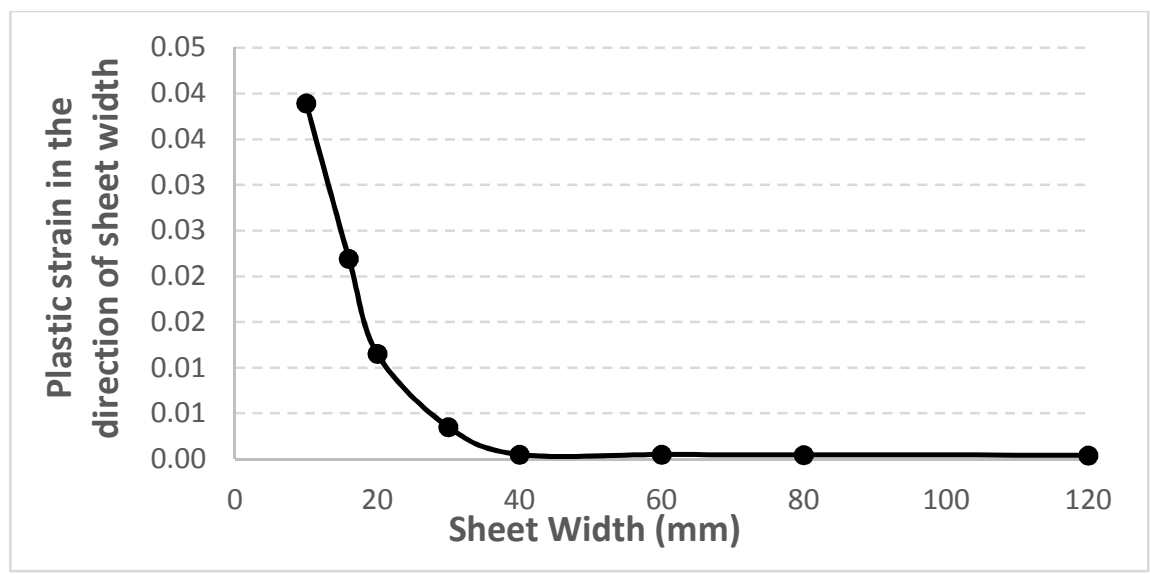

Fig.9. Plastic strain in the direction of sheet thickness for different sheet widths.

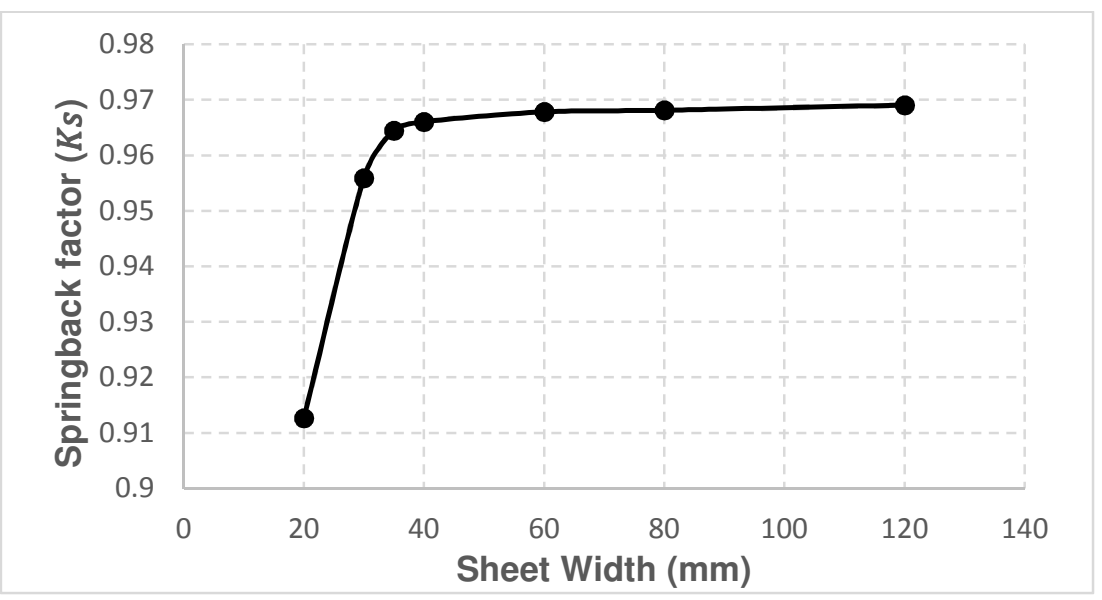

Fig.10. Relation between the springback factor $\left(\boldsymbol{K}_{\boldsymbol{S}}\right)$ and sheet width.

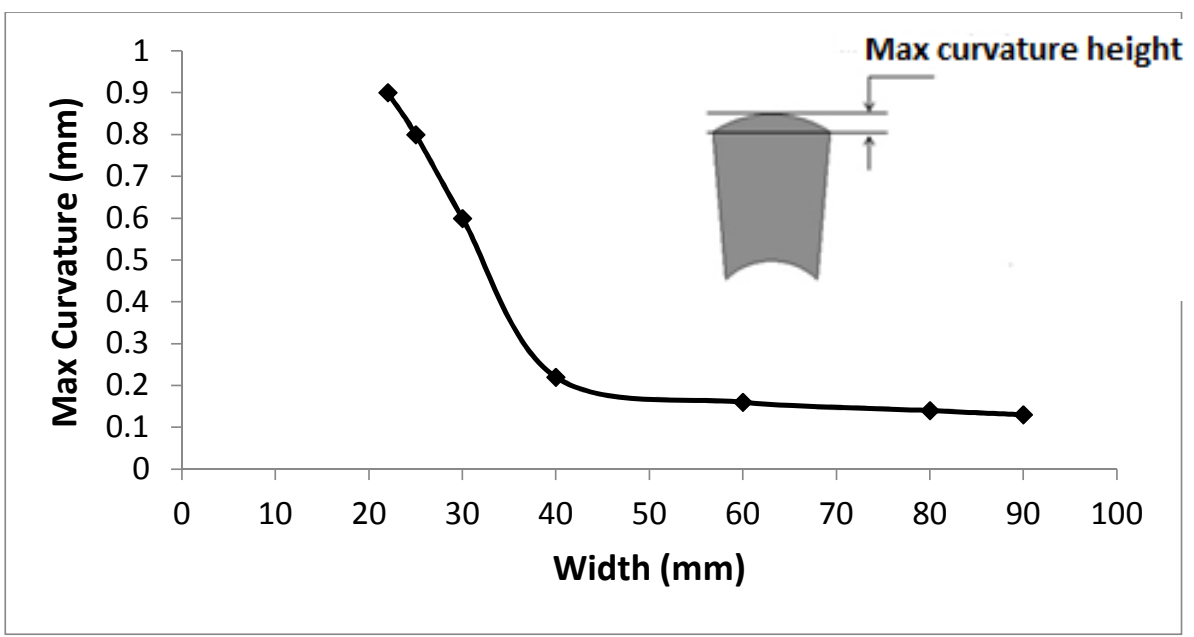

Fig.11. Maximum anticlastic curvature for different sheet widths. 

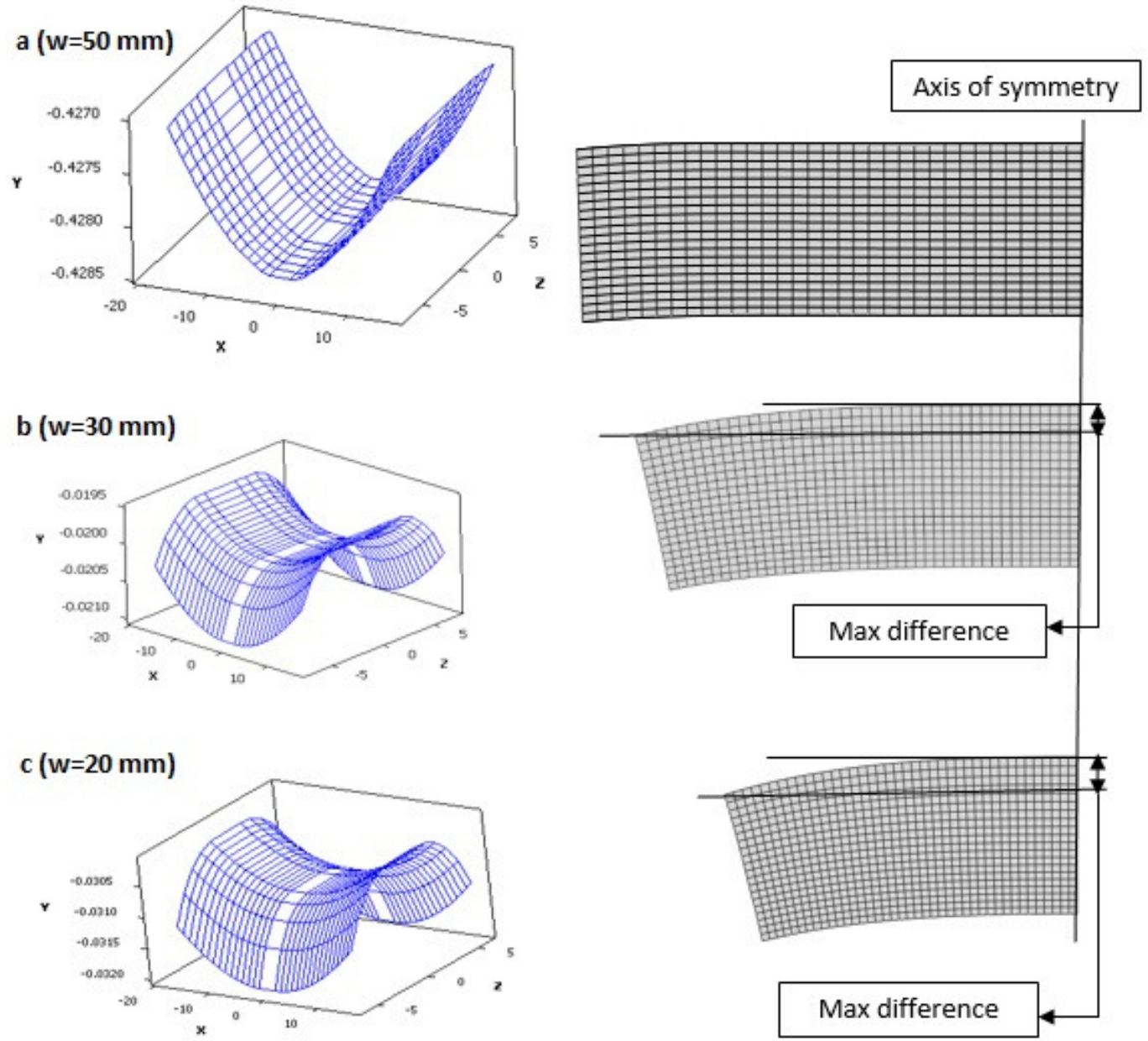

Fig.12. Anticlastic Curvature in case of plane strain condition (a), transition between plane strain and Plane stress (b) and plane stress condition (c).

Table 1. Material properties of low carbon steel AISI 1020 [20].

\begin{tabular}{|c|c|c|c|c|c|}
\hline $\begin{array}{c}(\mathrm{E}) \text { Young's } \\
\text { modulus } \\
(\mathrm{GPa})\end{array}$ & $\begin{array}{c}(v) \\
\text { Poisson's } \\
\text { ratio }\end{array}$ & $\begin{array}{c}\text { Yield } \\
\text { strength } \\
(\mathrm{MPa})\end{array}$ & $\begin{array}{c}\text { Tensile } \\
\text { Strength } \\
(\mathrm{MPa})\end{array}$ & $\begin{array}{c}(\mathrm{K}) \\
\text { Strength } \\
\text { coefficient }\end{array}$ & $\begin{array}{c}(\mathrm{n}) \text { Strain } \\
\text { hardening } \\
\text { exponent }\end{array}$ \\
\hline 207 & 0.3 & 295 & 395 & $600 \mathrm{MPa}$ & 0.21 \\
\hline
\end{tabular}

